\title{
Increased IL-10 mRNA expression in tumor- associated macrophage correlated with late stage of lung cancer
}

\author{
Rui Wang ${ }^{1 \dagger}$, Meng Lư ${ }^{2 \dagger}$, Haiquan Chen ${ }^{1 *}$, Sufeng Chen ${ }^{1}$, Xiaoyang Luo ${ }^{1}$, Ying Qin $^{2}$ and Jie Zhang ${ }^{1 *}$
}

\begin{abstract}
Background: Monocyte recruited into the tumor and maturation to tumor-associated macrophage (TAM). Interleukin-10(IL-10) is a potent immunosuppressive cytokine, which can be secreted from both primary tumor and stromal cells. However, there are controversies regarding its role in the progression of cancer. So it is important to isolate TAM from tumor cells to study the role of $I L-10$ in the progress of cancer. The aim of our study was to determine whether IL-10 expressed by TAM correlated with clinicopathological factors in NSCLC.

Methods: TAM in NSCLC was isolated by short-term culture in serum free medium with the modification to literature reports. The mRNA expression levels of $I L-10$, cathepsin $B$, cathepsin $S$, which were closely related with TAM according to the literatures, were evaluated by Quantitative real-time RT-PCR in 63 NSCLC. The relationships between their expression levels and clinicopathological features were investigated.

Results: We successfully achieved up to 95\% purity of TAM, derived from 63 primary lung cancer tissues. TAM expressed high levels of $I L-10$, cathepsin B in NSCLC. High levels of IL-10 in TAM significantly correlated with stage, tumor size, lymph node metastasis, lymphovascular invasion or histologic poor differentiation.

Conclusions: Our results revealed that TAM with high levels of $I L-10$ expression may play an important role in the progression of non-small cell lung cancer. The data also suggested that TAMs may involve in tumor immunosuppression through overexpressed IL-10. Additionally, the phenotype of isolated TAM can be potentially used to predict clinicopathological features as well.
\end{abstract}

Keywords: Lung cancer Tumor associated macrophages, IL-10

\section{Background}

Tumor-associated macrophages (TAMs) are the most abundant cancer stromal cells involved in the host immune system $[1,2]$. In recent years, increasing attention has focused on TAMs, unique macrophage populations that play pivotal roles in tumor immunosuppression, and provide a suitable microenvironment for cancer development and progression[3]. TAM infiltration has been found to be correlated with a worse outcome in several malignant tumors [4-9]. The possible mechanism by which

\footnotetext{
* Correspondence: hqchen1@yahoo.com; zhangjie2289@hotmail.com

† Contributed equally

${ }^{1}$ Center of Lung Cancer Prevention \& Treatment, Department of Thoracic

Surgery, Shanghai Cancer Hospital, Fudan University; Department of

Oncology, Shanghai Medical College, Fudan University, Shanghai 200032,

China

Full list of author information is available at the end of the article
}

TAMs support tumor progression and help the tumor evade immunosurveillance is through the release a spectrum of tumor promoting and immunosuppressive products.

Interleukin-10(IL-10), cathepsin B or cathepsin $S$ was reported to be closely associated with TAMs in recent literatures [10-12]. $I L-10$ is produced primarily by $\mathrm{T}$ cells, B cells, dendritic cells, and monocytes/macrophages[13]. Tumor-associated macrophages form a major component in a tumor, and have been suggested to play an essential role in the complex process of tumor-microenvironment coevolution and tumorigenesis [1]. Previous reports have also shown that TAMs produce high levels of $I L-10$, exhibit little cytotoxicity for tumor cells[14]. However, there are controversies regarding its role in the progression of cancer $[15,16]$. 
So it is important to isolate TAM from tumor cells to study the role of $I L-10$ in the progress of cancer.

By using DNA-microarray technology, recent study demonstrated that NSCLC patients with a high expression level of cathepsins in lung cancer tissue (both tumor cells and stroma cells) had a poor outcome [17]. Interestingly, it has been shown that TAM is the primary source of high levels of cathepsin activity in pancreatic, breast and prostate cancer animal models [10-12]. However, the significance of cathepsins expressed by TAM in NSCLC remains unknown.

In the present study, we assessed $I L-10$, cathepsin $B$ and cathepsin $S$ expression in TAMs, freshly isolated from lung tumor tissue, in correlation with clinicopathological factors in NSCLC.

\section{Materials and methods Subject characteristics}

63 paired peripheral blood samples and primary lung cancer tissues were collected from patients before or at the time of surgical resection at the Center for Lung Cancer Prevention and Treatment of Shanghai Cancer Hospital from June 2009 to March 2010. Data collected included age, sex, smoking history, histopathological diagnosis, TNM stage, lymphovascular invasion, pleural invasion, and tumor differentiation. Histological diagnoses, presence of lymphovascular invasion(LVI), and grade of differentiation were confirmed by two senior histopathologists. A consent form was signed by every patient or his/her legal representatives. This study was approved by the committees for Ethical Review of Research at Shanghai Cancer Hospital.

Histological diagnosis and grade of differentiation were determined in accordance with the World Health Organization criteria for lung cancer[18]. The pathologic tumor stage ( $\mathrm{p}$ stage) was determined according to the revised TNM classification of lung cancer[19].

\section{Isolation of tumor-associated macrophages}

TAMs were isolated from solid tumors according to literature reports [20-22]. Briefly, Tumor tissue was cut into $2 \mathrm{~mm}$ fragments, followed by collagenase digestion (0.3 mg/ml, Worthington Biochemical Corp, NJ, USA) for $1 \mathrm{~h}$ at $37^{\circ} \mathrm{C}$. The suspension was filtered through a $70 \mu \mathrm{m}$ stainless steel wire mesh to generate a single-cell suspension. The suspension was centrifuged and washed twice with PBS. Cells were left to adhere in serum-free RPMI 1640 for $40 \mathrm{~min}$. Nonadherent cells were washed away. Ninety-five percent of the remaining adherent cells were TAMs as assessed by morphology and macrophage specific marker CD68 positivity.

\section{Immunofluorescence}

TAMs were adhered to $24-$ well plate , fixed in $4 \%$ paraformaldehyde at room temperature for 5 minutes, washed with $\mathrm{PBS}$ twice, incubated with $1 \% \mathrm{BSA}$ at $37^{\circ} \mathrm{C}$ for 30 minutes to block nonspecific interactions, and then stained with primary antibodies to CD68 (1:100 dilution, sc-20060, Santa Cruz Biotechnology, CA, USA) at $4^{\circ} \mathrm{C}$ overnight. After several washes with PBS, the cells were incubated in an appropriate, rhodamine-labeled goat anti-mouse secondary antibody(Proteintech Group, Inc, Chicago ,USA) at room temperature for $1 \mathrm{~h}$. Nuclei of all cells were then stained with 4'6-diamidino-2-phenylindole(DAPI). Image was taken at $200 \times$ magnification on an Olympus-IX51 microscope. For each patient, 10 fields were imaged and measured for percentage of macrophage (CD68 positive cells/DAPI stained cells). Immunofluorescence was repeated in three randomly selected patients.

\section{Preparation normal macrophage}

Macrophage $(\mathrm{M} \phi)$ was obtained as described previously [20]. In brief, the mononuclear cells were isolated from peripheral blood matched with TAMs by Ficoll-Hypaque density gradient centrifugation (density, $1.077 \pm 0.001 \mathrm{~g} / \mathrm{ml}$, Axis-Shield, Oslo, Norway) at $450 \times \mathrm{g}$ for $30 \mathrm{~min}$ at room temperature. The mononuclear cells were washed thrice with PBS and plated at $1 \times 10^{7}$ in 6 - $\mathrm{cm}$ tissue culture dishe for $2 \mathrm{~h}$ in DMEM alone. Thereafter, the nonadherent cells were washed thrice with warm PBS and the adherent monocytes were cultured in DMEM containing 5\% FBS and $25 \mathrm{ng} / \mathrm{ml}$ human macrophage colony-stimulating factor((rhM-CSF, PeproTech, Rocky Hill, NJ, USA), The medium was changed every 2 days, and macrophage were obtained after 6 days in vitro cultivation.

RNA isolation and Quantitative real-time RT-PCR(QRT-PCR) Total RNA was isolated from TAMs and their matched macrophages by using RNeasy Mini Kit (Qiagen, Valencia, CA, USA) as described by the manufacturer's protocol. For mRNA analysis, an aliquot containing $2 \mu \mathrm{g}$ of total RNA was transcribed reversely using M-MLV reverse transcriptase (Promega, Madison, WI, USA). Specific primers (Genery, Shanghai, China) were used to amplify cDNA. QRT-PCR was done using SYBR Green PCR master mix (Applied Biosystems, Piscataway, NJ, USA). The primers for QRT-PCR were: $\beta$-actin forward (F) 5' ACCACA CCTTCTACAATGA3', $\beta$-actin reverse(R) 5'GTCATCTTCTCGCGGTTG3'; IL-10 F 5' AGAACCT GAAGACCCTCAGGC3', IL-10 R 5' CCACGGCCTT GCTCTTGTT 3'; cathepsin B F 5' TGCA GCGCTGG GTGGATCTA 3'; cathepsin B R 5' ATTGGCCAACACCAGCAGGC 3'; cathepsin S F 5' GCTTCTCTTGGT GTCCATAC 3', cathepsin S R 5' CATTACTGCGGGAATGAGAC 3'. The amplification protocol consisted of an initial $10 \mathrm{~min}$ denaturation step at $95^{\circ} \mathrm{C}$, followed by 40 cycles of PCR at $95^{\circ} \mathrm{C}$ for $15 \mathrm{~s}, 60^{\circ} \mathrm{C}$ for $1 \mathrm{~min}$ and detection by the ABI-Prism 7900HT Sequence Detection 
System (Applied Biosystems, Foster City, CA, USA). Each sample was assayed in triplicate. The comparative $C_{T}$ method ( $\Delta \Delta \mathrm{C}_{\mathrm{T}}$ method) was used to determine the quantity of the target sequences in TAM relative both to $\mathrm{M} \phi$ (calibrator) and to $\beta$-actin (an endogenous control). Relative expression levels were presented as the relative fold change and calculated using the formula: $2^{-\Delta \Delta \mathrm{CT}}=$ $2-\left(\Delta \mathrm{C}_{\mathrm{T}}{ }^{(\mathrm{TAM})}-\Delta \mathrm{C}_{\mathrm{T}}(\mathrm{M} \phi)\right.$ where each $\Delta \mathrm{C}_{\mathrm{T}}=\Delta \mathrm{C}_{\mathrm{T}}{ }^{\text {target }}$ $\Delta \mathrm{C}_{\mathrm{T}}^{\beta \text {-actin }}$.

\section{Immunohistochemistry}

For exact identification of IL-10 or cathepsin B expression in TAMs, serial sections were used to examine the expression of IL-10, cathepsin B in TAMs. Samples were fixed in $4 \%$ formaldehyde in PBS $(\mathrm{pH} 7.2)$ and paraffin embedded. 4- $\mu \mathrm{m}$ thickness was cut from each paraffin block. After dewaxing and rehydration, the sections were microwaved for antigen retrieval in $10 \mathrm{mmol} /$ liter citrate buffer ( $\mathrm{pH} 6.0$ ) for $10 \mathrm{~min}$, and then allowed to cool for 1 hour at room temperature. Endogenous peroxidase activity was blocked with hydrogen peroxide; Nonspecific binding was blocked by preincubation with $10 \%$ goat serum in PBS for 30 minutes at room temperature. Slides were incubated with the primary antibodies directed against monoclonal antihuman CD68 antibody (1:200 dilution, sc-20060, Santa Cruz, CA, USA), monoclonal anti-human IL-10 antibody (1:100 dilution, BA1201,Boster, WuHan, China) or polyclonal anti-human cathepsin B antibody (1:100 dilution, ab49232, Abcam, MA, USA). The results were visualized using the streptavidine-biotin immunoperoxidase detection kit and AEC chromogen (Maixin Bio, FuZhou, China) based on the manufacturer's instruction. Positive cells stained red. The negative control involved omission of the primary antibody.

\section{Statistical analysis}

Statistical analysis software (Prism 5.0, GraphPad Software Inc, La Jolla, CA, USA and SPSS Version 13.0 software, SPSS Inc, Chicago, IL, USA) was used to perform the analyses. Data are expressed as median (range). The Mann-Whitney test was used for the comparison between TAM and normal macrophage. The correlation between $I L-10$ or cathepsin $B$ expression and clinicopathologic factors was analyzed by Mann-Whitney test. Multivariate logistic regression was performed to evaluate the relationships between the pathological stage (with early and late stage as dependent variables) and covariates (age, sex, tobacco use, tumor histology and $I L-10$ expression in TAMs). For this analysis, the median value of $I L-10$ was chosen as the cut-off point for dividing the patients into the two groups. Two-tailed $\mathrm{P}$ value less than 0.05 was considered statistically significant.

\section{Results}

Patients characteristics

The patient characteristics are described in Table 1. Patients (40 males and 23 females) had a mean age of $58.8 \pm 1.1$ years. Fifty-four patients had a smoking history, and forty-six were non-smokers. Adenocarcinoma was the most common tumor type (54\%) followed by squamous cell carcinoma (32\%). 30 patients $(48 \%)$ were stage I (early stage), and the remaining 34 patients were (52\%) stages II, III or IV (late stage) of the disease.

\section{Table 1 characteristics for the patients included in this} study

\begin{tabular}{|c|c|c|c|}
\hline characteristic & & No. ${ }^{a}(\mathrm{~N}=63)$ & $\%$ \\
\hline $\begin{array}{l}\text { Age/years(Median, } \\
\text { range) }\end{array}$ & & $58(37-76)$ & \\
\hline \multicolumn{4}{|l|}{ Sex } \\
\hline & Male & 40 & 63. \\
\hline & Female & 23 & 36 \\
\hline
\end{tabular}

Tobacco use

$\begin{array}{ccc}\text { Current } & 22 & 35 \\ \text { Former } & 12 & 19 \\ \text { Never } & 29 & 46\end{array}$

Histology

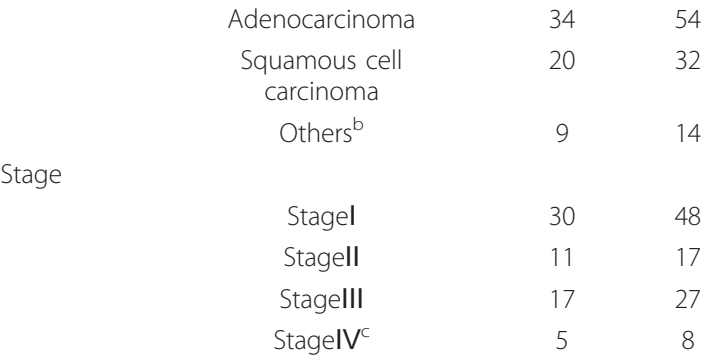

Lymph node metastasis

$\begin{array}{ccc}\text { N0 } & 42 & 67 \\ N 1 / N 2 & 21 & 33\end{array}$

Pleural invasion

Negative $\quad 43 \quad 68$

Lymphovascular

Positive $\quad 20 \quad 32$

invasion

$\begin{array}{lll}\text { Negative } & 51 & 81\end{array}$

Positive $\quad 12 \quad 9$

Histologic

differentiation

$\begin{array}{ccc}\text { Well/Moderate } & 30 & 48 \\ \text { Poor } & 26 & 41 \\ \text { not available }^{\mathrm{d}} & 7 & 11\end{array}$

${ }^{a}$ Number for all except age.

${ }^{\mathrm{b}}$ Include 2 Large cell carcinoma, 2 Carcinoid, 1 malignant clear cell sugar tumor, 1 Sarcomatoid carcinoma, and 3 malignancy, but type undetermined. 'Stage IV was found incidentally during the operation or only for biopsy.

d Include Carcinoid, malignant clear cell sugar tumor, Sarcomatoid carcinoma, multiple primary lung cancer. 


\section{Isolation and identification of tumor-associated} macrophages

In our study, 71 NSCLC samples were collected and TAMs were successful isolated from all samples. However, cell number of TAMs isolated from 8 NSCLC was inadequate for gene expression analysis, and excluded from this study. So TAMs from 63 NSCLC were finally analyzed. The successful rate was $89 \%(63 / 71)$. Each sample weight ranged from $10 \mathrm{mg}$ to $200 \mathrm{mg}$ and the cell number of TAMs collected ranged from $5 \times 10^{5}$ to $1 \times$ $10^{7}$ per $100 \mathrm{mg}$ tumor tissue.

TAMs from lung cancer tissue had an irregular shape and projections (Figure 1A). To confirm that the cell isolated from the lung cancer tissue were TAMs without contamination by fibroblasts or tumor cells, staining for the macrophage specific marker CD68 was performed. Over ninety-five percent of the cells stained positively for each randomly selected patient (Figure 1B).

The mRNA expression levels of IL-10, cathepsin B and cathepsin $S$ in normal macrophages

We performed a time course study to show the expression level of $I L-10$, cathepsin $B$ and cathepsin $S$ in monocytes changes after culture in medium with rhM-CSF. Our study showed the expression level of IL-10, cathepsin B and cathepsin $S$ showed no significant changes in the time dependent study. (All p > 0.05) (Figure 2A). We also performed dose depedent study of rhM-CSF to see whether the expression level of IL-10, cathepsin B and cathepsin $\mathrm{S}$ were affected or not. Our study showed that the dose of rhM-CSF did not affect the expression level of IL-10, cathepsin B and cathepsin S (Figure 2B).

\section{The mRNA expression levels of IL-10, cathepsin B and cathepsin $S$ in TAMs}

The mRNA expression levels of $I L-10$, cathepsin $B$ and cathepsin $S$ in TAMs were analyzed using QRT-PCR, compared with matched normal macrophages from the 63 patients. To explore the best time point for analyzing the expression level of $I L-10$, cathepsin $B$ and cathepsin $S$, a time course study was done. After adhere to plastic for $20 \mathrm{~min}, 40 \mathrm{~min}, 60 \mathrm{~min}$ and $90 \mathrm{~min}$, the expression level of IL-10 were: $28.3 \pm 2.3 ; 28.1 \pm 1.1 ; 24.6 \pm 2.1$; $14.7 \pm 2.9$ respectively, and the purity of TAMs were: $100 \%$, 97\%, 95\%, 84\% respectively (staining for the macrophage specific marker CD68 was performed). After $60 \mathrm{~min}$, tumor cells and fibroblast began to adhere, the purity decreased rapidly. So we chose 40 min as the time point for adherence, which is consistent with previous reports [23] (Figure 3).

Compared with the expression in macrophage, $I L-10$ and cathepsin $B$ were significantly upregulated $(\mathrm{p}<0.05)$. After normalized to macrophages, the median values (range) of each gene in TAM were: $I L-10,30.5(0.6-530.3)$ and cathepsin B, 11.9(0.6-69.1) (Figure 4 A-B). There were no significant differences in the level of cathepsin $S$

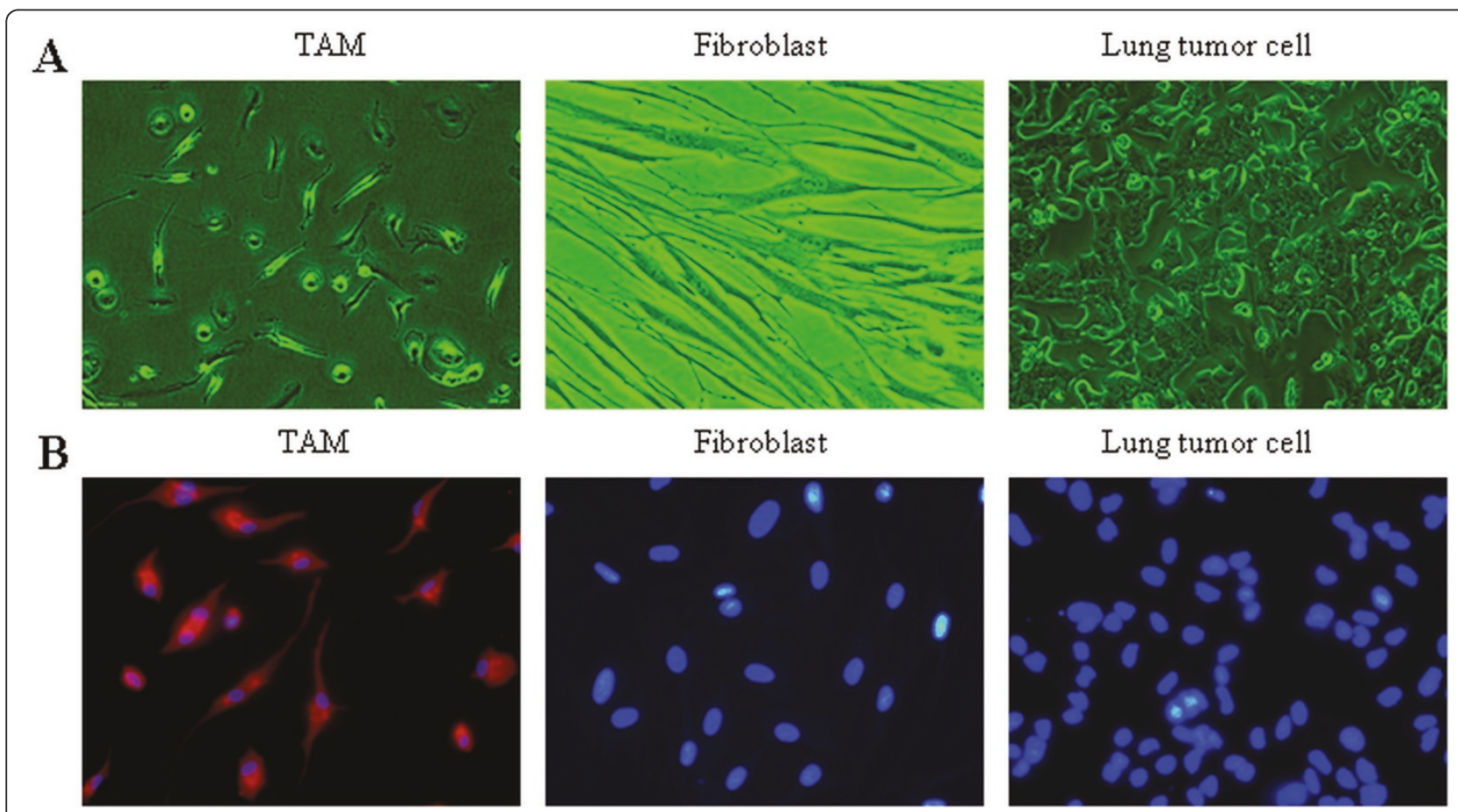

Figure 1 Characterization of tumor-associated macrophage. A. Representative cell morphology of tumor-associated macrophages, TAM, fibroblast and lung tumor cell. B. Immunofluorescent was used to distinguish macrophage, fibroblast and lung tumor cell with antibodies targeting CD68 (red), nuclei stained with DAPI (blue). Original magnification, $\times 400$. 


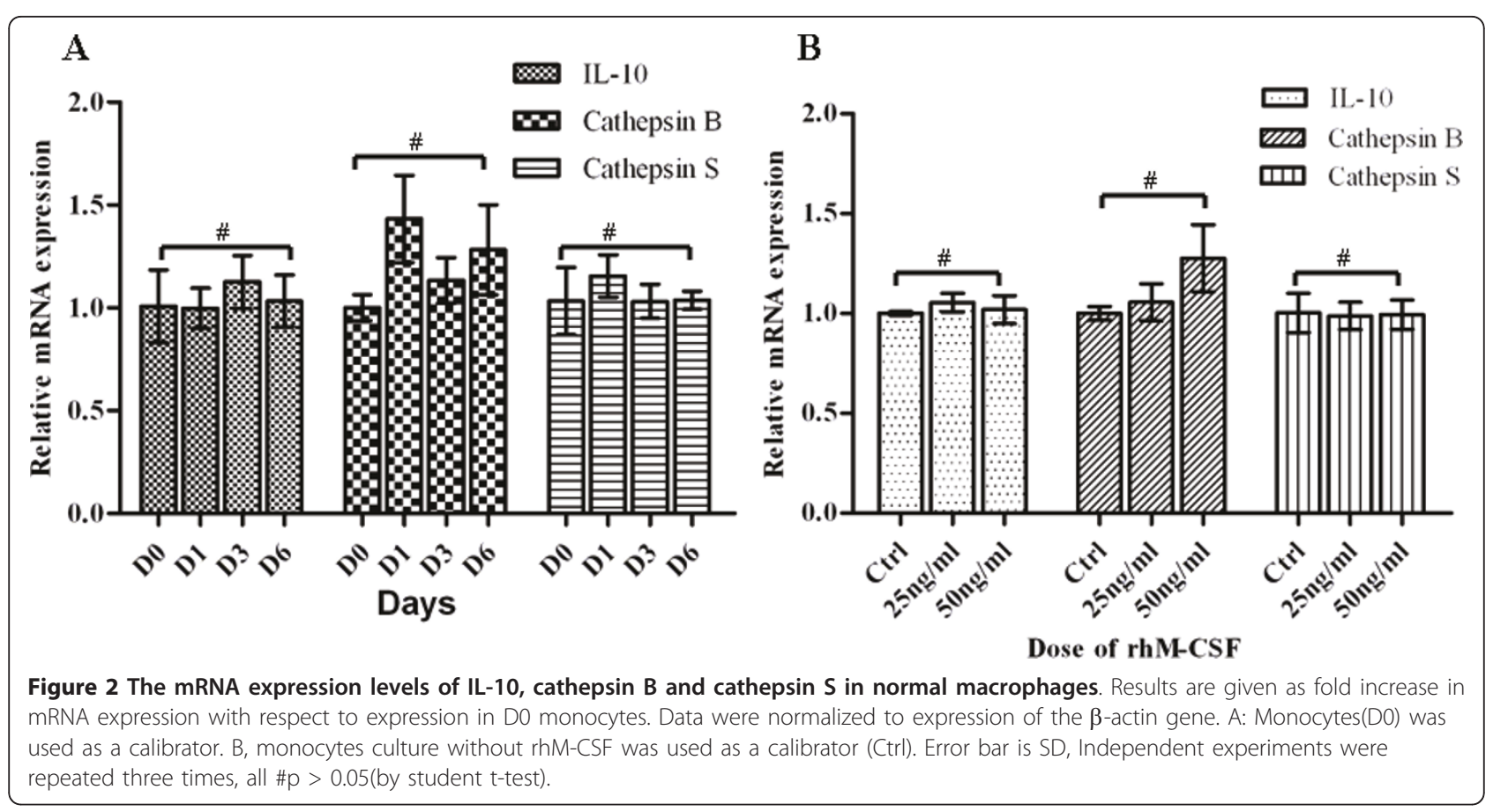

between the TAMs $(0.85(0.04-4.49))$ and the macrophages (Figure 4C).

\section{Immunohistochemistry}

To confirm whether TAMs express $I L-10$ and cathepsin $B$ in protein level, 6 NSCLC (3 late stage (IIIA) and 3 early stage (Ia- Ib)) were randomly selected to perform

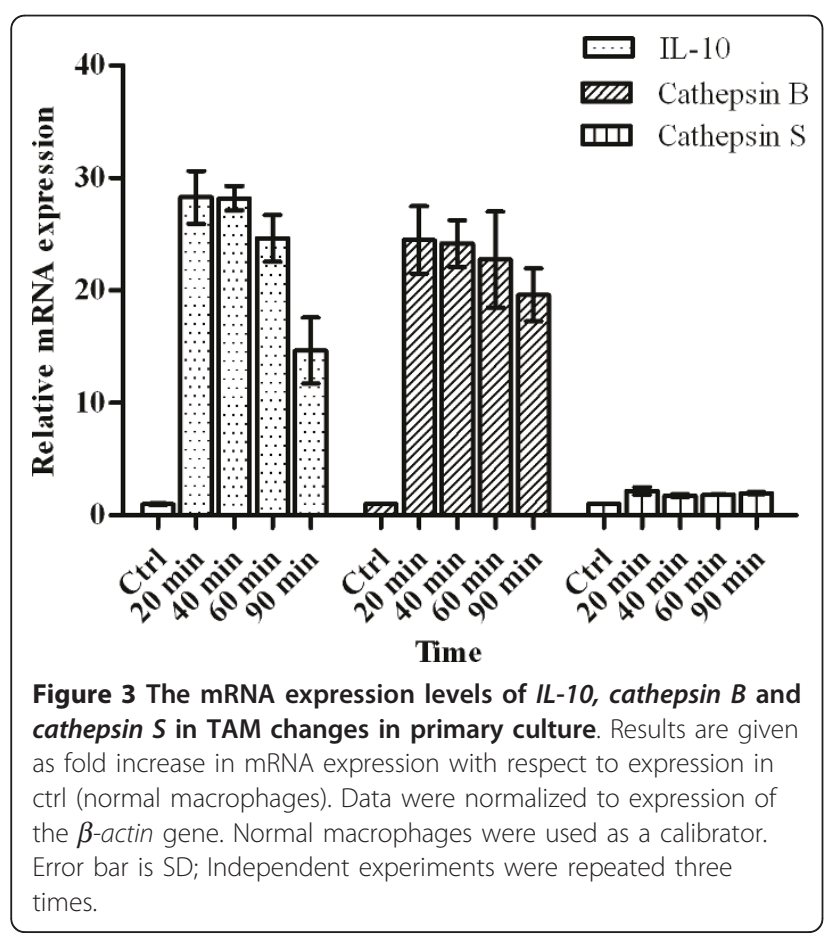

IHC using antibody against CD68, $I L-10$ and cathepsin $B$ on serial sections. We demonstrated that almost all CD68 positive cells co-expressing $I L-10$, which in line with the QRT-PCR results that the IL-10 mRNA expression level is high (Figure $5 \mathrm{~A}-\mathrm{B}$ ). The $I L-10$ expression was negative by IHC in 3 early stage NSCLC, which in line with the QRT-PCR results that the $I L-10$ mRNA expression level below the median (30.5) in 3 early stage NSCLC. Expression of cathepsin B in macrophage was observed in 5 of 6 cases. Among macrophages expressing cathepsin $B$, only a small portion of the cells showed strong positive (Figure $5 \mathrm{C}$-D) and not associated with stage of disease.

The correlation between IL-10, cathepsin B expression in TAM and clinicopathologic factors

The correlation between $I L-10$, cathepsin B expression in TAM and clinicopathologic factors was shown in Table 2. A strongly positive correlation between $I L-10$ mRNA expression in TAM and tumor stage was seen. Increased expression levels of $I L-10$ in TAM were seen in NSCLC patients with late stage (stage II, III and IV). When multivariate logistic regression analysis was performed, $I L-10$ expression in TAMs was shown to be an independent predictive factor for late stage disease (Table 3 ).

The increased mRNA expression of $I L-10$ was also associated with lymph node metastasis, lymphovascular invasion, pleural invasion and poor differentiation ( $\mathrm{p}<$ $0.0001, \mathrm{p}=0.010, \mathrm{p}=0.017 \mathrm{p}=0.001$, respectively).

A correlation between cathepsin B mRNA expression in TAM with NSCLC tumor T status was found ( $\mathrm{p}=0.037)$. 


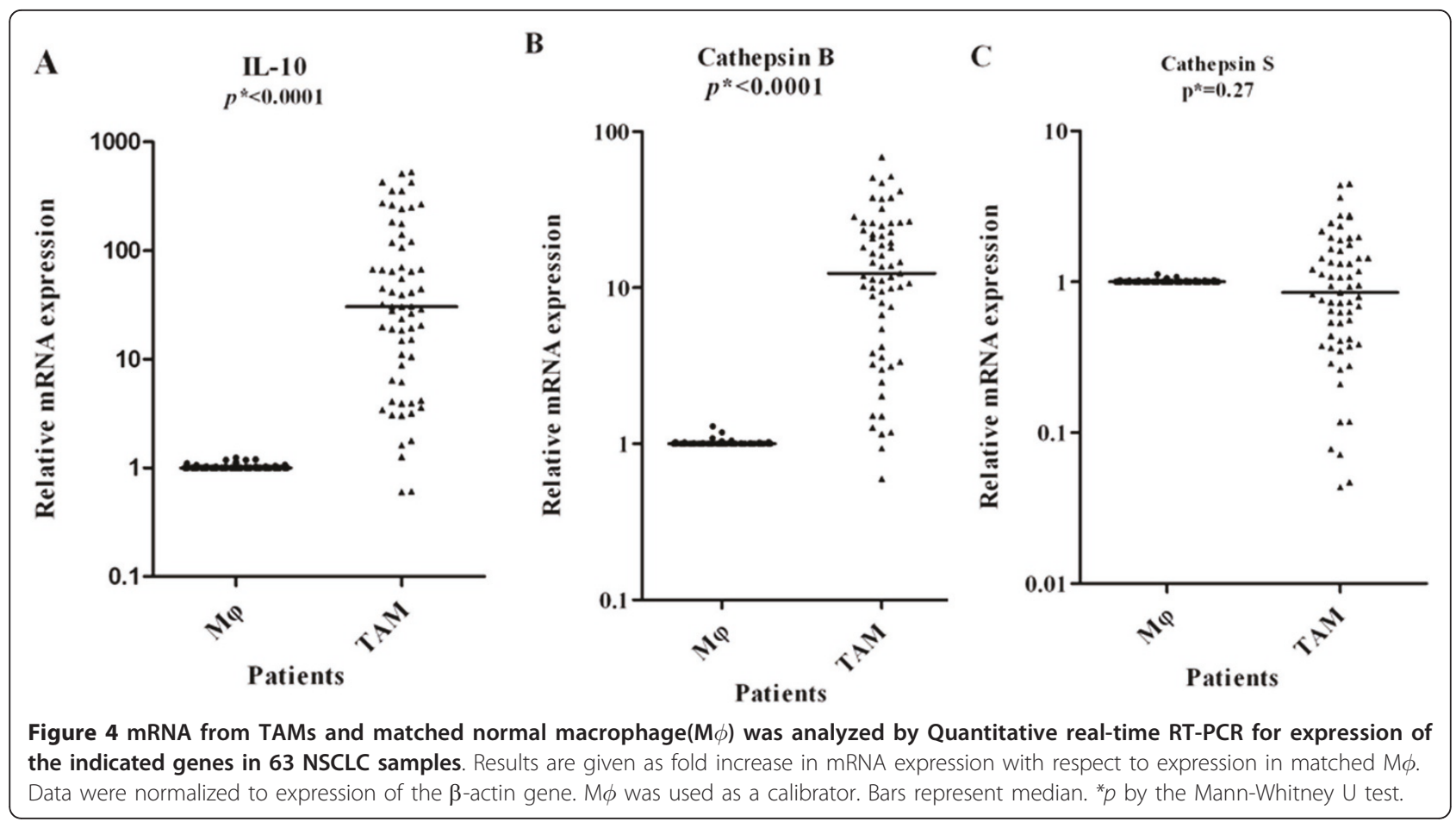

Otherwise, there was no significant relationship between the mRNA expression of cathepsin $B$ with any other clinicopathological factors (all $\mathrm{p}>0.05$ ).

\section{Discussion}

Increased infiltration of TAMs into NSCLC correlates with a poor prognosis $[5,9]$. However, the mechanisms for this effect remain unclear. TAM derived molecules that function to suppress immune activation, promote extracellular matrix (ECM) remodeling may play important roles in NSCLC progression.

In the present study, the rational we selected $I L-10$, cathepsin $B$ or cathepsin $S$, is that they were reported to be closely associated with TAMs in recent literatures $[10-12,24]$. IL-10 is widely known as an potent immunosuppressive cytokine associated with cancer $[13,25]$. It is produced by a number of cells, including tumor cells and TAMs[14,25]. Cathepsins B, cathepsin S, proteolytic enzymes, were thought to facilitate the breakdown of basement membranes thereby promoting cancer cell invasion into surrounding normal tissues. TAM expressed cathepsin $B$ or cathepsin $S$ in pancreatic islet, breast or prostate cancer animal models. In our study, we showed, TAM expressed high levels of $I L-10$, cathepsin $B$, but not cathepsin $S$ in NSCLC.

Our study suggested that increased $I L-10$ expression of TAM in NSCLC patients correlated with late stage disease (stage II, III and IV), lymph node metastases, pleural invasion, lymphovascular invasion and poor differentiation. Although recent animal model studies indicated that cathepsin B or cathepsin $S$ expressed by TAM play an important role in tumor progression $[10,11]$, and we also found cathepsin $B$ upregulated in TAM, we failed to demonstrate any correlation between cathepsin $B$ in TAM and stage, lymph nodal metastasis, pleural invasion or differentiation in NSCLC.

TAMs are derived from blood monocytes that are attracted to a tumor by cytokines and chemokines[14]. In the tumor microenvironment, monocytes differentiate into a distinct macrophage phenotype, which is characterized by the production of high level of $I L-10$. TAM with high $I L-10$ expression level may tune inflammatory responses and adaptive Th2 immunity, exhibit anti-inflammatory and tissue remodeling functions and thereby, to favor tumor progression[14]. We demonstrated that NSCLC patients with late stage disease had a higher level of $I L-10$ expression in TAM, which further supports this hypothesis.

$I L-10$ is a potent immunosuppressive factor that may promote lung cancer growth by suppressing macrophage function and enabling tumors to evade immunosurveillance[26]. The potential importance of $I L-10$ in cancer progression is supported by reports of an association between high $I L-10$ levels in serum or in tumors and worse survival in lung cancer patients[15]. However, other authors demonstrated that lack of $I L-10$ expression by the tumor was associated with a worse survival in patients with stage I NSCLC [16]. The reason for these conflicting results might be that, both tumor cells 


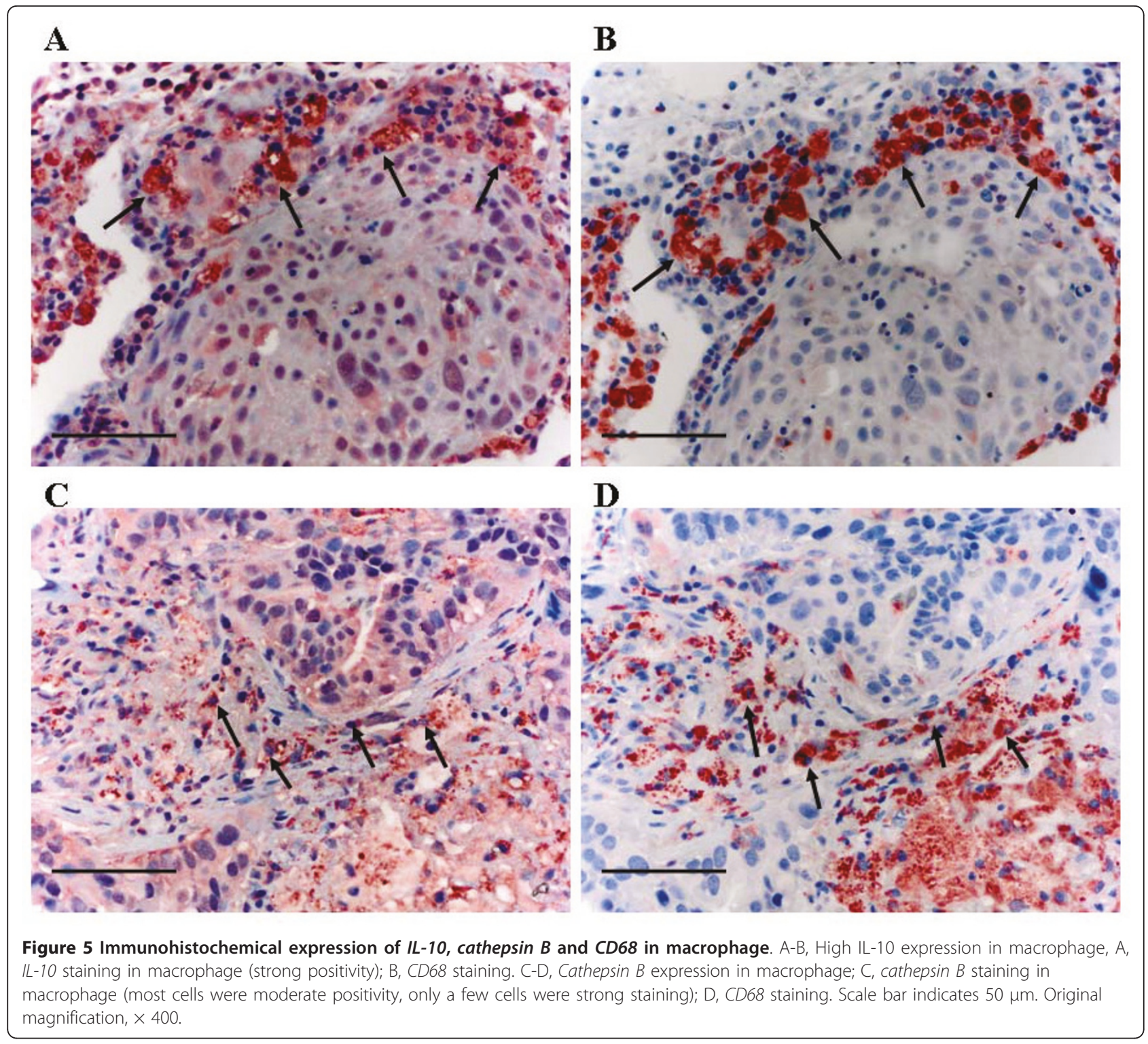

and stromal(including macrophage) cells can secrete $I L$ 10. Additionally, Wagner $\mathrm{S}$ et al identified that macrophage was the major source of $I L-10$ in gliomas[27]. So it is important to isolate TAM from tumor cells to study the role of $I L-10$ in the progression of cancer. In our study, we demonstrated the phenotype of isolated TAM was closely associated with clinicopathological features. We can predict tumor size, lymph nodal metastasis and pleural invasion through.IL-10 expression in isolated TAM. We also found that the high expression of $I L-10$ in TAM was associated with poorly differentiation, which highlighted a significance role of $I L-10$ secreted by TAM in tumor aggressiveness.

A crucial step of cancer invasion and metastasis is the destruction of basement membrane by proteases. Recent studies showed invasion of cancer cell is increased by the proteases secreted from TAMs. Cathepsin B or cathepsin $S$ has been implicated in the progression of various human cancers, including bladder, breast, prostate and lung cancers $[17,28-30]$. The cellular source of this protease in human cancers, consisting of both tumor cells and stromal cells (e.g., fibroblasts, endothelial cells, and TAMs), has remained elusive. Studies using animal models have demonstrated that TAMs are the primary source of high levels of cathepsin B or cathepsin $S$ in prostate, pancreatic islet cancers, and mammary tumors, and its expression by TAMs plays critical roles in multiple stages of tumor growth and metastasis[10,12,29]. Our studies demonstrated that TAM isolated from NSCLC overexpressed cathepsin $B$ but not cathepsin $S$, and the cathepsin $B$ levels were not associated with NSCLC stage, lymph metastasis, lymphovascular invasion or histological differentiation. 
Table 2 Genes expression of TAM in relationship with clinicopathological factors

\begin{tabular}{|c|c|c|c|c|c|}
\hline \multirow[b]{2}{*}{ Variables } & \multirow[b]{2}{*}{$\mathrm{N}$} & \multicolumn{2}{|l|}{ IL-10 } & \multicolumn{2}{|l|}{ Cathepsin B } \\
\hline & & Median(Range) & $p^{*}$ value & Median (Range) & $p^{*}$ value \\
\hline \multicolumn{6}{|l|}{ age } \\
\hline$<58$ & 26 & $31.3(3.05-530.3)$ & 0.252 & $10.9(0.9-51.9)$ & 0.41 \\
\hline$\geq 58$ & 37 & $30.5(0.6-511.6)$ & & $14.5(0.6-69.1)$ & \\
\hline \multicolumn{6}{|l|}{ Gender } \\
\hline Male & 40 & $31.3(1.3-530.3)$ & 0.607 & $14.9(0.9-69.1)$ & 0.061 \\
\hline Female & 23 & 19.9(0.6-426.1) & & $10.1(0.6-37.9)$ & \\
\hline \multicolumn{6}{|l|}{ Smoking history } \\
\hline Never & 29 & $30.5(0.6-426.1)$ & 0.699 & $10.1(0.6-51.9)$ & 0.067 \\
\hline Former or current & 34 & $31.2(1.3-530.3)$ & & $14.9(1.5-69.1)$ & \\
\hline \multicolumn{6}{|l|}{ Histology } \\
\hline Adenocarcinoma & 34 & $42.9(0.6-530.3)$ & 0.045 & $12.7(0.6-69.1)$ & 0.41 \\
\hline Squamous cell carcinoma & 20 & $17.1(1.3-354.3)$ & & $16.6(1.5-41.7)$ & \\
\hline Others & 9 & $41.2(6.4-511.6)$ & & $10.2(4.2-26.7)$ & \\
\hline \multicolumn{6}{|l|}{ Pathological stage } \\
\hline Stage I & 30 & $9.7(0.6-140.8)$ & 0.016 & $13.1(0.6-69.1)$ & 0.066 \\
\hline Stagell & 11 & 28.9(1.8-511.6) & & 13.6(3.1-41.7) & \\
\hline Stagelll & 17 & $177.7(23.5-530.3)$ & & $11.8(1.2-51.9)$ & \\
\hline StagelV & 5 & 249.9(55.4-429.9) & & $10.1(3.6-25.9)$ & \\
\hline \multicolumn{6}{|l|}{ T status } \\
\hline $\mathrm{T} 1$ & 15 & $4.1(0.6-263.6)$ & $<0.0001$ & $9.9(0.6-22.7)$ & 0.037 \\
\hline $\mathrm{T} 2-3$ & 48 & $42.9(1.6-530.3)$ & & $14.2(0.9-69.1)$ & \\
\hline \multicolumn{6}{|l|}{ Lymph node metastasis } \\
\hline$N(+)$ & 21 & $119.1(6.1-530.3)$ & $<0.0001$ & $13.6(1.2-46.9)$ & 0.466 \\
\hline$N(-)$ & 42 & $19.2(0.6-273.8)$ & & $11.1(0.6-69.1)$ & \\
\hline \multicolumn{6}{|l|}{ Lymphovascular invasion } \\
\hline $\operatorname{LVI}(+)$ & 12 & $93.1(6.2-530.3)$ & 0.01 & $14.2(0.9-37.8)$ & 0.92 \\
\hline LVI(-) & 51 & $26.5(0.6-429.9)$ & & $11.1(0.6-69.1)$ & \\
\hline \multicolumn{6}{|l|}{ Pleural invasion } \\
\hline $\mathrm{PL}(+)$ & 20 & $55.8(14.9-530.3)$ & 0.002 & $14.2(0.9-69.1)$ & 0.376 \\
\hline$P L(-)$ & 43 & $19.9(0.6-354.9)$ & & $11.1(0.6-51.9)$ & \\
\hline \multicolumn{6}{|l|}{ Differentiation } \\
\hline Well or Moderately & 30 & $17.3(0.6-429.9)$ & 0.001 & 13.0(0.6-69.1) & 0.961 \\
\hline poorly & 26 & $113.1(1.6-530.3)$ & & $11.9(1.2-37.9)$ & \\
\hline
\end{tabular}

${ }^{*} p$ by the Mann-Whitney $\mathrm{U}$ test.

\section{Conclusions}

Interleukin-10 expression in tumor-associated macrophages correlates with disease aggressiveness of non-small cell lung cancer. We plan to conduct further studies to analyze the relationship between $I L-10$ in TAM and survival. The study concerning regulation of $I L-10$ in TAM is ongoing too. It will help to clarify and understand the possible mechanisms IL-10 secreted by TAM in the progression of NSCLC.

Table 3 Logistic regression analysis of the association between tumor stage and clinicopathological features $(n=63)$

\begin{tabular}{|c|c|c|c|c|c|}
\hline & B & SEM & Chi-squared & p-value & OR $(95 \% \mathrm{Cl})$ \\
\hline Sex & 0.241 & 1.110 & 0.037 & 0.847 & $1.239(0.141-10.922)$ \\
\hline Age & -0.063 & 0.040 & 2.484 & 0.115 & 0.939(0.868-1.015) \\
\hline Tobacco use & 1.173 & 1.102 & 1.133 & 0.287 & $3.231(0.373-28.005)$ \\
\hline Histology & 0.292 & 0.531 & 0.303 & 0.582 & $1.339(0.473-3.793)$ \\
\hline High level IL-10 expression in TAM & 2.952 & 0.742 & 15.844 & 0.0001 & 19.137(4.474-81.859) \\
\hline
\end{tabular}

The dependent variable is early- or late-stage group The independent variables included sex ( $0=$ female; $1=$ male), age (continuous variable, in yrs), Tobacco use $(0=$ Current, $1=$ Former, $2=$ Never $)$, histology $(1=$ adenocarcinoma; $2=$ squamous cell carcinoma; $3=$ others $)$ and IL-10 expression $(0=$ low $(<30.5) ; 1=$ high ( $\geq 30.5)$. OR: odds ratio; $\mathrm{Cl}$ : confidence interval. 


\section{Acknowledgements}

This work is supported, in part, by National Natural Science Foundation of China (30800404), Shanghai Rising-Star Program (09QA1401200), Pujiang Talent Grant, (to J. Z), Young Investigator Grant from Shanghai Municipal Health Bureau.and Basic-clinical medicine grant (to $\mathrm{H}-\mathrm{Q} \mathrm{C}$ ). We thank Shannon Wyszomierski for her editorial assistance.

\section{Author details}

${ }^{1}$ Center of Lung Cancer Prevention \& Treatment, Department of Thoracic Surgery, Shanghai Cancer Hospital, Fudan University; Department of Oncology, Shanghai Medical College, Fudan University, Shanghai 200032, China. ${ }^{2}$ Institute for Nutritional Sciences, Shanghai Institutes for Biological Sciences, Chinese Academy of Sciences; Graduate School of the Chinese Academy of Sciences, 200031, China.

\section{Authors' contributions}

RW and $\mathrm{ML}$ designed and performed the experiment and prepared the manuscript. HQC and JZ supervised the project. YQ, SFC, XYL acquired their authorship for assistance in collecting samples and analyzing data. All authors have read and approved the final manuscript.

\section{Competing interests}

The authors declare that they have no competing interests.

Received: 5 January 2011 Accepted: 20 May 2011

Published: 20 May 2011

\section{References}

1. Pollard JW: Tumour-educated macrophages promote tumour progression and metastasis. Nat Rev Cancer 2004, 4(1):71-78.

2. Balkwill F, Mantovani A: Inflammation and cancer: back to Virchow? Lancet 2001, 357(9255):539-545.

3. Joyce JA, Pollard JW: Microenvironmental regulation of metastasis. Nat Rev Cancer 2009, 9(4):239-252.

4. Ohno S, Ohno Y, Suzuki N, Kamei T, Koike K, Inagawa H, Kohchi C, Soma G, Inoue $\mathrm{M}$ : Correlation of histological localization of tumor-associated macrophages with clinicopathological features in endometrial cancer. Anticancer Res 2004, 24(5C):3335-3342.

5. Takanami I, Takeuchi K, Kodaira S: Tumor-associated macrophage infiltration in pulmonary adenocarcinoma: association with angiogenesis and poor prognosis. Oncology 1999, 57(2):138-142.

6. Leek RD, Lewis CE, Whitehouse R, Greenall M, Clarke J, Harris AL: Association of macrophage infiltration with angiogenesis and prognosis in invasive breast carcinoma. Cancer Res 1996, 56(20):4625-4629.

7. Lissbrant IF, Stattin P, Wikstrom P, Damber JE, Egevad L, Bergh A: Tumor associated macrophages in human prostate cancer: relation to clinicopathological variables and survival. Int J Oncol 2000, 17(3):445-451.

8. Hanada T, Nakagawa M, Emoto A, Nomura T, Nasu N, Nomura Y: Prognostic value of tumor-associated macrophage count in human bladder cancer. Int J Urol 2000, 7(7):263-269.

9. Chen JJ, Lin YC, Yao PL, Yuan A, Chen HY, Shun CT, Tsai MF, Chen CH, Yang PC: Tumor-associated macrophages: the double-edged sword in cancer progression. J Clin Oncol 2005, 23(5):953-964.

10. Gocheva V, Wang HW, Gadea BB, Shree T, Hunter KE, Garfall AL, Berman T, Joyce JA: IL-4 induces cathepsin protease activity in tumor-associated macrophages to promote cancer growth and invasion. Genes Dev 2010, 24(3):241-255.

11. Lindahl $C$, Simonsson M, Bergh A, Thysell E, Antti $H$, Sund M, Wikstrom P: Increased levels of macrophage-secreted cathepsin $S$ during prostate cancer progression in TRAMP mice and patients. Cancer Genomics Proteomics 2009, 6(3):149-159.

12. Vasiljeva O, Papazoglou A, Kruger A, Brodoefel H, Korovin M, Deussing J, Augustin N, Nielsen BS, Almholt K, Bogyo M, et al: Tumor cell-derived and macrophage-derived cathepsin $B$ promotes progression and lung metastasis of mammary cancer. Cancer Res 2006, 66(10):5242-5250.

13. de Waal Malefyt R, Yssel H, Roncarolo MG, Spits H, de Vries JE: Interleukin10. Curr Opin Immunol 1992, 4(3):314-320.

14. Coffelt SB, Hughes R, Lewis CE: Tumor-associated macrophages: effectors of angiogenesis and tumor progression. Biochim Biophys Acta 2009, 1796(1):11-18
15. Hatanaka H, Abe Y, Kamiya T, Morino F, Nagata J, Tokunaga T, Oshika Y, Suemizu $H$, Kijima $H$, Tsuchida T, et al: Clinical implications of interleukin (IL)-10 induced by non-small-cell lung cancer. Ann Oncol 2000, 11(7):815-819.

16. Soria JC, Moon C, Kemp BL, Liu DD, Feng L, Tang X, Chang YS, Mao L, Khuri FR: Lack of interleukin-10 expression could predict poor outcome in patients with stage I non-small cell lung cancer. Clin Cancer Res 2003, 9(5):1785-1791.

17. Cordes C, Bartling B, Simm A, Afar D, Lautenschlager C, Hansen G, Silber RE, Burdach S, Hofmann HS: Simultaneous expression of Cathepsins B and K in pulmonary adenocarcinomas and squamous cell carcinomas predicts poor recurrence-free and overall survival. Lung Cancer 2009, 64(1):79-85.

18. Beasley MB, Brambilla E, Travis WD: The 2004 World Health Organization classification of lung tumors. Semin Roentgenol 2005, 40(2):90-97.

19. Detterbeck FC, Boffa DJ, Tanoue LT: The new lung cancer staging system. Chest 2009, 136(1):260-271

20. Solinas G, Schiarea S, Liguori M, Fabbri M, Pesce S, Zammataro L, Pasqualini F, Nebuloni M, Chiabrando C, Mantovani A, et al: Tumorconditioned macrophages secrete migration-stimulating factor: a new marker for M2-polarization, influencing tumor cell motility. J Immunol 2010, 185(1):642-652.

21. Sierra JR, Corso S, Caione L, Cepero V, Conrotto P, Cignetti A, Piacibello W Kumanogoh A, Kikutani H, Comoglio PM, et al: Tumor angiogenesis and progression are enhanced by Sema4D produced by tumor-associated macrophages. J Exp Med 2008, 205(7):1673-1685.

22. Duff MD, Mestre J, Maddali S, Yan ZP, Stapleton P, Daly JM: Analysis of gene expression in the tumor-associated macrophage. J Surg Res 2007, 142(1):119-128.

23. Biswas SK, Gangi L, Paul S, Schioppa T, Saccani A, Sironi M, Bottazzi B, Doni A, Vincenzo B, Pasqualini F, et al: A distinct and unique transcriptional program expressed by tumor-associated macrophages (defective NF-kappaB and enhanced IRF-3/STAT1 activation). Blood 2006, 107(5):2112-2122.

24. Mohamed MM, Cavallo-Medved D, Rudy D, Anbalagan A, Moin K, Sloane BF: Interleukin-6 increases expression and secretion of cathepsin B by breast tumor-associated monocytes. Cell Physiol Biochem 2010, 25(23):315-324.

25. Salazar-Onfray F: Interleukin-10: a cytokine used by tumors to escape immunosurveillance. Med Oncol 1999, 16(2):86-94.

26. Torisu-Itakura H, Lee JH, Huynh Y, Ye X, Essner R, Morton DL: Monocytederived IL-10 expression predicts prognosis of stage IV melanoma patients. J Immunother 2007, 30(8):831-838.

27. Wagner S, Czub S, Greif M, Vince GH, Suss N, Kerkau S, Rieckmann P, Roggendorf W, Roosen K, Tonn JC: Microglial/macrophage expression of interleukin 10 in human glioblastomas. Int J Cancer 1999, 82(1):12-16.

28. Eijan AM, Sandes EO, Riveros MD, Thompson S, Pasik L, Mallagrino H, Celeste F, Casabe AR: High expression of cathepsin B in transitional bladder carcinoma correlates with tumor invasion. Cancer 2003, 98(2):262-268.

29. Fernandez PL, Farre X, Nadal A, Fernandez E, Peiro N, Sloane BF, Shi GP, Chapman HA, Campo E, Cardesa A: Expression of cathepsins B and $S$ in the progression of prostate carcinoma. Int J Cancer 2001, 95(1):51-55.

30. Maguire TM, Shering SG, Duggan CM, McDermott EW, O'Higgins NJ, Duffy MJ: High levels of cathepsin B predict poor outcome in patients with breast cancer. Int J Biol Markers 1998, 13(3):139-144.

doi:10.1186/1756-9966-30-62

Cite this article as: Wang et al:: Increased IL-10 mRNA expression in tumor-associated macrophage correlated with late stage of lung cancer. Journal of Experimental \& Clinical Cancer Research 2011 30:62. 